\title{
Characterization and comparison of EST-SSR and TRAP markers for genetic analysis of the Japanese persimmon Diospyros kaki
}

\author{
C. Luo, F. Zhang, Q.L. Zhang, D.Y. Guo and Z.R. Luo \\ Key Laboratory of Horticultural Plant Biology (MOE), \\ Huazhong Agricultural University, Wuhan, China \\ Corresponding author: Z.R. Luo \\ E-mail: luozhr@mail.hzau.edu.cn \\ Genet. Mol. Res. (2013) Ahead of Print \\ Received July 7, 2012 \\ Accepted October 3, 2012 \\ Published January 9, 2013 \\ DOI http://dx.doi.org/10.4238/2013.January.9.3
}

\begin{abstract}
We developed and characterized expressed sequence tags (ESTs)-simple sequence repeats (SSRs) and targeted region amplified polymorphism (TRAP) markers to examine genetic relationships in the persimmon genus Diospyros gene pool. In total, we characterized 14 EST-SSR primer pairs and 36 TRAP primer combinations, which were amplified across 20 germplasms of 4 species in the genus Diospyros. We used various genetics parameters, including effective multiplex ratio (EMR), diversity index (DI) and marker index (MI), to test the utility of these markers. TRAP markers gave higher EMR (24.85) but lower DI (0.33), compared to EST-SSRs $(\mathrm{EMR}=3.65$, DI $=0.34)$. TRAP gave a very high MI (8.08), which was about eight times than the MI of EST-SSR (1.25). These markers were utilized for phylogenetic inference of 20 genotypes of Diospyros kaki Thunb. and allied species, with a result that all kaki genotypes clustered closely and three allied species formed an independent group. These markers could be further exploited for large-scale genetic relationship inference.
\end{abstract}

Key words: Expressed sequence tags-simple sequence repeats (EST-SSRs); Targeted region amplified polymorphism (TRAP); Diospyros kaki Thunb.; Genetic relationship 
C. Luo et al.

\section{INTRODUCTION}

In recent years, in silico approaches have been effectively utilized to develop and characterize the functional genomic markers amplifying genic regions. These markers provide a functional insight into gene-based diversity analysis. Expressed sequence tags (ESTs) have been effectively utilized for the development of these markers and have been subsequently used in the characterization of germplasm (Lima et al., 2010; Kumar Yadav et al., 2011). Simple sequence repeats (SSRs), also called microsatellites, are repetitive stretches of DNA varying from 1-6 bp in length, whereas targeted region amplified polymorphism (TRAP), uses the anchored and arbitrary primers to target the functional gene regions (Hu and Vick, 2003). Essentially, it derives an 18-mer primer from the EST and pairs it with an arbitrary primer that targets the intronic and/or exonic region (AT- or GC- rich core) (Li and Quiros, 2001).

ESTs present a novel way of developing SSRs and TRAP markers in a less time consuming way and finding more practical applicability in the inference of genetic diversity and linking traits. The distinguishing features of SSR markers and their suitability in the genotyping of populations lies in many factors, namely their high information content, codominant inheritance, high reproducibility and even distribution along chromosomes (Powell et al., 1996a). EST-derived markers have been well documented and applied in characterization that involves mainly the identification of QTL of important agronomic traits, genetic mapping, genetic diversity, and comparative genomics (Liu et al., 2005; Miklas et al., 2006; Alwala et al., 2006; Hu et al., 2007; Cloutier et al., 2009; Durand et al., 2010). In short, they have been widely used in the study of model fruit plants such as citrus, apple and cucumber (Chen et al., 2008; Gasic et al., 2009; Hu et al., 2010).

Japanese persimmon (or Oriental persimmon, Diospyros kaki Thunb.) is a major commercial and deciduous fruit tree that is believed to have originated in China (Yakushiji and Nakatsuka, 2007). In recent years, several molecular markers were exploited for genetic analysis of Diospyros genus. Guo and Luo $(2006,2008,2011)$ developed several SSR primers using ISSR-suppression PCR and biotinylated (GA) 10 and streptavidin-coated magnetic beads in persimmon. Soriano et al. (2006) exploited 37 SSR markers from an enriched genomic library. Du et al. (2009a) compared four molecular markers (IRAP, REMAP, SSAP, and AFLP) for genetic analysis in Diospyros. However, information is lacking on development of EST-SSR and TRAP in persimmon. In an earlier study, we effectively obtained information on EST-SSR, SNP and SSR-FDMs using the 9467 D. kaki Thunb. ESTs recently reported (Sablok et al. 2011). In the present study, we focused on the identification and characterization of the primer pairs of EST-SSR and TRAP that are able to delineate and infer genotyping in $D$. kaki.

\section{MATERIAL AND METHODS}

\section{Plant materials and DNA isolation}

A total of 20 genotypes of Diospyros spp were used for characterization which included 7 Chinese, 10 Japanese (D. kaki Thunb.) and 3 related species (Table 1). All samples were collected from different sites and are currently preserved at the Persimmon Repository, Huazhong Agricultural University, Wuhan, China. Genomic DNA isolation was standardized using fresh leaves and the method proposed by Doyle and Doyle (1990). 
EST-SSR and TRAP markers in persimmon

Table 1. List of 20 genotypes of Diospyros spp used in present study.

\begin{tabular}{|c|c|c|c|c|c|}
\hline Code & Accessions & Species & Ploidy & Astringent type* & Origin \\
\hline 1 & Eshi 1 & D. kaki Thunb. & $2 n=6 x=90$ & PCNA & China \\
\hline 2 & Sifang-tianshi & D. kaki Thunb. & $2 n=6 x=90$ & PCNA & China \\
\hline 3 & Baogai-tianshi & D. kaki Thunb. & $2 n=6 x=90$ & PCNA & China \\
\hline 4 & Tongpenshi & D. kaki Thunb. & $2 n=6 x=90$ & PCA & China \\
\hline 5 & Damopan & D. kaki Thunb. & $2 n=6 x=90$ & PCA & China \\
\hline 6 & Yunyang-dongshi & D. kaki Thunb. & $2 n=6 x=90$ & PCA & China \\
\hline 7 & Xiangxi-tianshi & D. kaki Thunb. & $2 n=6 x=90$ & PCNA & Japan \\
\hline 8 & Huashi 1 & D. kaki Thunb. & $2 n=6 x=90$ & PVA & Japan \\
\hline 9 & Fuyuu & D. kaki Thunb. & $2 n=6 x=90$ & PCNA & Japan \\
\hline 10 & Maekawa-Jirou & D. kaki Thunb. & $2 n=6 x=90$ & PCNA & Japan \\
\hline 11 & Hana-gosho & D. kaki Thunb. & $2 n=6 x=90$ & PCNA & Japan \\
\hline 12 & Oku-gosho & D. kaki Thunb. & $2 n=6 x=90$ & PCNA & Japan \\
\hline 13 & Youhou & D. kaki Thunb. & $2 n=6 x=90$ & PCNA & Japan \\
\hline 14 & Nishimura-wase & D. kaki Thunb. & $2 n=6 x=90$ & PVNA & Japan \\
\hline 15 & Akagaki & D. kaki Thunb. & $2 n=6 x=90$ & PVNA & Japan \\
\hline 16 & Hiratane-nashi & D. kaki Thunb. & $2 n=9 x=135$ & PVA & Japan \\
\hline 17 & Chekiang persimmon & D. glaucifolia Metc. & $2 n=2 x=30$ & - & China \\
\hline 18 & Suruga & D. kaki Thunb. & $2 n=6 x=90$ & PCNA & Japan \\
\hline 19 & Oily persimmon & D. oleifera Cheng & $2 n=2 x=30$ & - & China \\
\hline 20 & Date plum & D. lotus L. & $2 n=2 x=30$ & - & China \\
\hline
\end{tabular}

*Persimmon can be classified into four types depending on the nature of the fruit's astringency loss at maturity and the change in flesh color: PCNA = pollination constant non-astringent; PVNA = pollination-variant non-astringent; $\mathrm{PVA}=$ pollination-variant astringent, and $\mathrm{PCA}=$ pollination-constant astringent.

\section{EST-SSR marker development}

The EST assembly and EST-SSR primers are described in our previous study (Sablok et al., 2011). PCR amplification were performed using PCRs $(20 \mu \mathrm{L})$ that contained 20 ng genomic DNA, $100 \mu \mathrm{M}$ dNTPs, $1 \mathrm{X}$ buffer, $1.5 \mathrm{mM} \mathrm{MgCl}, 1 \mathrm{U}$ Taq DNA polymerase, and $0.8 \mu \mathrm{M}$ of each primer. The PCR thermal profile involved denaturation at $94^{\circ} \mathrm{C}$ for $2 \mathrm{~min}$, followed by 35 cycles of $94^{\circ} \mathrm{C}$ for $45 \mathrm{~s}, 55^{\circ}-60^{\circ} \mathrm{C}$ (primer Tm standardization according to GC of primer) for 1 min, $72^{\circ} \mathrm{C}$ for $75 \mathrm{~s}$, and a final $5 \mathrm{~min}$ extension step at $72^{\circ} \mathrm{C}$ on a Biometra T-Professional PCR (Germany). PCR fragments were separated on $6 \%$ denaturing polyacrylamide gels with a constant power at $60 \mathrm{~W}$ followed by silver staining for visualization of the amplicons as per the protocol described by Bassam et al. (1991) with slight modification as per Charters et al. (1996).

\section{TRAP marker development}

For the development of TRAP markers, six fixed primers were derived from persimmon ESTs that were selected for homology to proanthocyanidin metabolism related genes of other plant species using the TBLASTX program, by comparing the sequences against the non-redundant NCBI nucleotide database with a cut-off $\mathrm{E}$ value of $10^{-60}$ and $80 \%$ minimum identity score. Primers were designed using Primer Premier 5.0 (Lalitha, 2000). The six arbitrary primers selected for the present study were taken from Li and Quiros (2001). PCR amplification was performed in $15 \mu \mathrm{L}$ PCR mixtures containing $40 \mathrm{ng}$ genomic DNA, $1 \mathrm{X}$ reaction buffer, $1.7 \mathrm{mM} \mathrm{MgCl}{ }_{2}, 0.3 \mathrm{mM}$ dNTPs, $0.1 \mu \mathrm{M}$ arbitrary primer, $0.5 \mu \mathrm{M}$ fixed primer, and 1.5 U Taq DNA polymerase. PCR was performed by initially denaturing template DNA at $94^{\circ} \mathrm{C}$ for $4 \mathrm{~min}$; then 5 cycles at $94^{\circ} \mathrm{C}$ for $45 \mathrm{~s}, 40^{\circ} \mathrm{C}$ for $45 \mathrm{~s}$ and $72^{\circ} \mathrm{C}$ for $1 \mathrm{~min}$; followed by 35 cycles at $94^{\circ} \mathrm{C}$ for $45 \mathrm{~s}, 52^{\circ} \mathrm{C}$ (Primer Tm depends) for $45 \mathrm{~s}$, and $72^{\circ} \mathrm{C}$ for $1 \mathrm{~min}$; and a final 
C. Luo et al.

extension step at $72^{\circ} \mathrm{C}$ for $7 \mathrm{~min}$. PCR fragments were separated on $6 \%$ denaturing polyacrylamide gels with a constant power at $60 \mathrm{~W}$ by the same method as for EST-SSR.

\section{Data collection and analysis}

EST-SSR and TRAP profiles were scored for the presence and absence of the bands as 1 and 0 , respectively, in all genotypes. Each polymorphic DNA band at a particular position on the gel was treated as a separate character and scored as allele size. Only robust bands were scored, while ambiguous bands were ignored and excluded from the analysis. To infer the suitability of the proposed marker system diversity index (DI), effective multiplex ratio (EMR; number of polymorphic products from a single amplification reaction) and marker index (MI; the product of effective multiplex ratio and diversity index) were calculated for each marker according to Powell et al. (1996b) and Geuna et al. (2003).

Genetic similarity values based on the Dice similarity coefficient were calculated, and cluster analysis was performed to construct dendrograms using the unweighted pair-group method with arithmetic averages (UPGMA) and the SAHN clustering modules. Correlation among the different matrices produced by different marker systems was done using the MXCOMP module of the Mantel test. Goodness-of-fit was calculated by the COPH and MXCOMP programs. All analyses were performed with the NTSYSpc 2.10e software (Rohlf, 2000).

\section{RESULTS}

\section{EST-SSR and TRAP analysis}

Of the 116 designed EST-SSR primers, 71 showed robust PCR amplification and 14 of them revealed polymorphism among 20 persimmon genotypes, indicating a polymorphic rate of $19.72 \%$ of the primers for characterization and genotyping of Diospyros genus. The sequences and amplification of these polymorphic EST-SSR primers are shown in Table 2, and a sample amplification profile of the EST-SSRs is displayed in Figure 1. The number of alleles detected by the 14 SSR loci ranged from 4 to 14 with an average of 7.86. The percent of polymorphic bands ranged from 83.33 to $100 \%$ with an average of $97.42 \%$ in 14 pairs of primers.

A total of 36 TRAP primer combinations revealed 2184 PCR amplicons, of which 2072 PCR amplicons were found polymorphic, showing a high percentage of polymorphism (94.87\%). A representative gel profile of the TRAP markers is shown in Figure 2. The individual number of bands detected by individual primer combinations varied from 33 (DK6+EM3) to 110 (DK7+EM1) with an average of 60.67. These two primer combinations were also responsible for the minimum (31 in DK6+EM3) and the maximum (108 in DK7+EM1) number of polymorphic bands produced for an average of 57.56 polymorphic bands per primer combination (Tables 3 and 4).

\section{EST-SSR markers versus TRAP markers}

A comparative analysis was done within the marker system and the results are summarized in Table 4. We found that TRAP markers showed a higher percentage of amplicon profiling (2184 amplicons) compared to EST-SSR (118 amplicons), but the percentage of polymorphism as 
EST-SSR and TRAP markers in persimmon

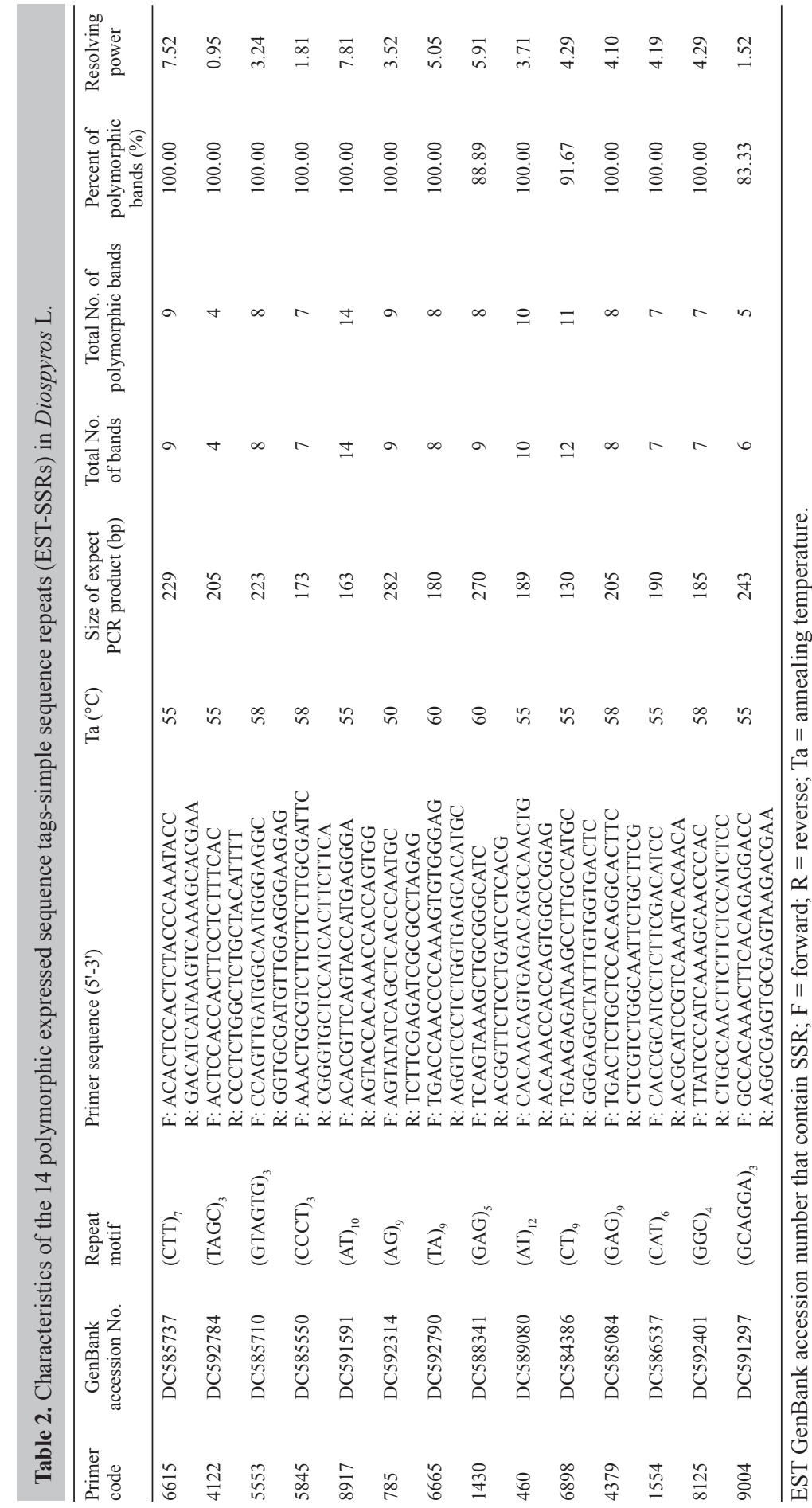


C. Luo et al.

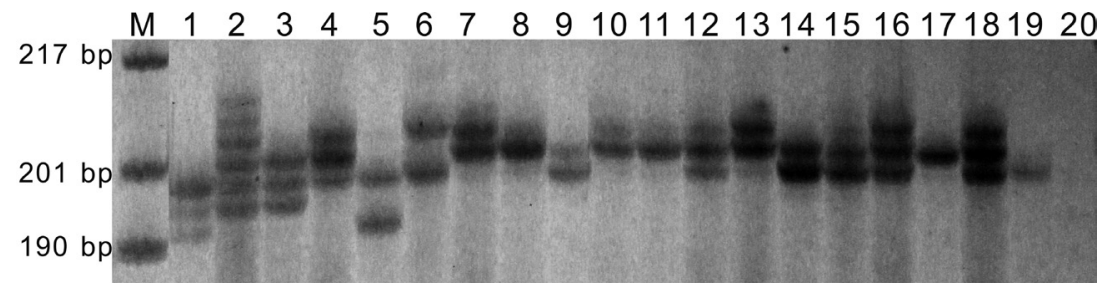

Figure 1. Profile of expressed sequence tags-simple sequence repeats amplification using primer 4379. Lanes 1 to 20 = persimmon genotypes Eshi 1, Sifang-tianshi, Baogai-tianshi, Tongpenshi, Damopan, Yunyang-dongshi, Xiangxi-tianshi, Huashi 1, Fuyuu, Maekawa-Jirou, Hana-gosho, Oku-gosho, Youhou, Nishimura-wase, Akagaki, Hiratane-nashi, Chekiang persimmon, Suruga, Oily persimmon, and Date plum, respectively. Lane $M=$ pBR322 DNA/Mspl marker.

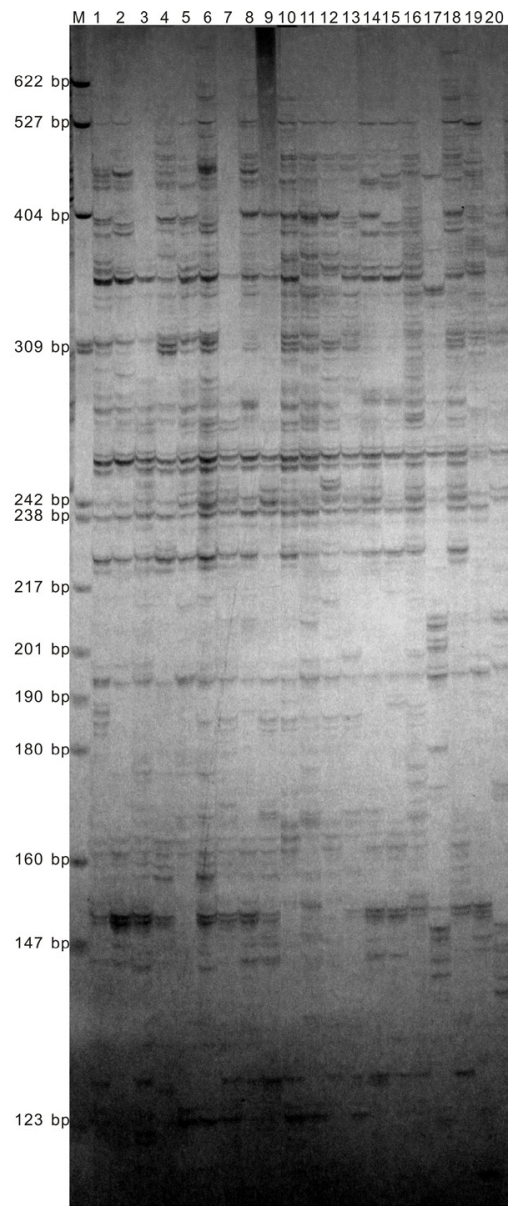

Figure 2. Profile of targeted region amplified polymorphism amplification using DK7+Em1 primer combination. Lanes 1 to 20 = persimmon genotypes Eshi 1, Sifang-tianshi, Baogai-tianshi, Tongpenshi, Damopan, Yunyangdongshi, Xiangxi-tianshi, Huashi 1, Fuyuu, Maekawa-Jirou, Hana-gosho, Oku-gosho, Youhou, Nishimura-wase, Akagaki, Hiratane-nashi, Chekiang persimmon, Suruga, Oily persimmon, and Date plum, respectively. Lane $M=$ pBR322 DNA/Mspl marker. 
EST-SSR and TRAP markers in persimmon

Table 3. Characteristics of targeted region amplified polymorphism primers in Diospyros L.

\begin{tabular}{|c|c|c|c|c|c|c|c|c|}
\hline Fixed primers sequence & $\begin{array}{l}\text { Name of } \\
\text { target gene }\end{array}$ & $\mathrm{Ta}\left({ }^{\circ} \mathrm{C}\right)$ & $\begin{array}{c}\text { GenBank } \\
\text { accession No. }\end{array}$ & $\begin{array}{l}\text { Arbitrary } \\
\text { primers* }\end{array}$ & $\begin{array}{l}\text { Total No. } \\
\text { of bands }\end{array}$ & $\begin{array}{c}\text { Total No. } \\
\text { of polymorphic } \\
\text { bands }\end{array}$ & $\begin{array}{c}\text { Percent of } \\
\text { polymorphic } \\
\text { bands }(\%)\end{array}$ & $\begin{array}{c}\text { Resolving } \\
\text { power }\end{array}$ \\
\hline \multicolumn{9}{|l|}{ DK5 } \\
\hline \multirow[t]{6}{*}{ GCCCACTTCT-ACTGGTTCT } & \multirow{6}{*}{$\begin{array}{l}\text { Anthocyanidin } \\
\text { reductase }\end{array}$} & \multirow[t]{6}{*}{51.2} & \multirow[t]{6}{*}{ DC586464 } & Em1 & 43 & 43 & 100.00 & 22.29 \\
\hline & & & & Em2 & 39 & 37 & 94.87 & 16.76 \\
\hline & & & & Em3 & 39 & 37 & 94.87 & 14.38 \\
\hline & & & & Em4 & 66 & 62 & 93.94 & 31.05 \\
\hline & & & & Em5 & 56 & 50 & 89.29 & 25.14 \\
\hline & & & & Em6 & 46 & 44 & 95.65 & 22.29 \\
\hline \multirow{6}{*}{$\begin{array}{l}\text { DK6 } \\
\text { GGGACCCTG-ACAATAAGAA }\end{array}$} & \multirow{6}{*}{$\begin{array}{l}\text { Anthocyanidin } \\
\text { reductase }\end{array}$} & \multirow[t]{6}{*}{51.9} & \multirow[t]{6}{*}{ DC586464 } & Em1 & 58 & 57 & 98.28 & 30.19 \\
\hline & & & & Em2 & 34 & 32 & 94.12 & 12.95 \\
\hline & & & & Em3 & 33 & 31 & 93.94 & 14.86 \\
\hline & & & & Em4 & 70 & 66 & 94.29 & 36.29 \\
\hline & & & & Em5 & 84 & 83 & 98.81 & 41.52 \\
\hline & & & & Em6 & 65 & 65 & 100.00 & 32.10 \\
\hline \multirow{6}{*}{$\begin{array}{l}\text { DK7 } \\
\text { GAGGACGCA-TTGCTTACA }\end{array}$} & \multirow{6}{*}{$\begin{array}{l}\text { MYB } \\
\text { transcription } \\
\text { factor }\end{array}$} & \multirow[t]{6}{*}{52} & \multirow[t]{6}{*}{ DC587740 } & Em1 & 110 & 108 & 98.18 & 50.667 \\
\hline & & & & Em2 & 54 & 50 & 92.59 & 19.71 \\
\hline & & & & Em3 & 84 & 80 & 95.24 & 38.29 \\
\hline & & & & Em4 & 45 & 39 & 86.67 & 15.05 \\
\hline & & & & Em5 & 50 & 48 & 96.00 & 21.05 \\
\hline & & & & Em6 & 49 & 45 & 91.84 & 19.43 \\
\hline \multirow{6}{*}{$\begin{array}{l}\text { DK8 } \\
\text { CGATGTGGA-AAGAGTTGC }\end{array}$} & \multirow{6}{*}{$\begin{array}{l}\text { MYB } \\
\text { transcription } \\
\text { factor }\end{array}$} & \multirow[t]{6}{*}{51.1} & \multirow[t]{6}{*}{ DC587740 } & Em1 & 78 & 74 & 94.87 & 40.19 \\
\hline & & & & Em2 & 54 & 49 & 90.74 & 20.38 \\
\hline & & & & Em3 & 64 & 59 & 92.19 & 26.77 \\
\hline & & & & Em4 & 58 & 57 & 98.28 & 24.29 \\
\hline & & & & Em5 & 57 & 51 & 89.47 & 22.57 \\
\hline & & & & Em6 & 42 & 41 & 97.62 & 19.52 \\
\hline \multirow{6}{*}{$\begin{array}{l}\text { DK9 } \\
\text { CAGGTTTAC-GATTCAAGGC }\end{array}$} & \multirow[t]{6}{*}{ Laccase } & \multirow[t]{6}{*}{53.1} & \multirow[t]{6}{*}{ DC585535 } & Em1 & 79 & 76 & 96.20 & 32.48 \\
\hline & & & & Em2 & 55 & 48 & 87.27 & 23.14 \\
\hline & & & & Em3 & 64 & 59 & 92.19 & 28.86 \\
\hline & & & & Em4 & 77 & 66 & 85.71 & 31.14 \\
\hline & & & & Em5 & 99 & 95 & 95.96 & 43.71 \\
\hline & & & & Em6 & 90 & 84 & 93.33 & 36.86 \\
\hline \multirow{6}{*}{$\begin{array}{l}\text { DK10 } \\
\text { CTCTTCCTT-TCCATTCCC }\end{array}$} & \multirow[t]{6}{*}{ Laccase } & \multirow[t]{6}{*}{51.3} & \multirow[t]{6}{*}{ DC585535 } & Em1 & 70 & 70 & 100.00 & 32.86 \\
\hline & & & & Em2 & 88 & 88 & 100.00 & 46.10 \\
\hline & & & & Em3 & 59 & 59 & 100.00 & 30.10 \\
\hline & & & & Em4 & 53 & 48 & 90.57 & 25.90 \\
\hline & & & & Em5 & 33 & 33 & 100.00 & 17.33 \\
\hline & & & & Em6 & 39 & 38 & 97.44 & 19.81 \\
\hline
\end{tabular}

*Arbitrary reverse primer sequences were obtained from Li and Quiros (2001).

Table 4. Levels of polymorphism and comparison of the marker information obtained with expressed sequence tagssimple sequence repeat (EST-SSR) and targeted region amplified polymorphism (TRAP) markers in 20 genotypes.

\begin{tabular}{lccccrr}
\hline & $\begin{array}{c}\text { Total number } \\
\text { of bands }\end{array}$ & $\begin{array}{c}\text { Total No. of } \\
\text { polymorphic } \\
\text { bands (\%) }\end{array}$ & $\begin{array}{c}\text { Average No. of } \\
\text { total bands/ } \\
\text { assay unit }\end{array}$ & $\begin{array}{c}\text { Average No. of } \\
\text { polymorphic bands/ } \\
\text { assay unit }\end{array}$ & DI $^{\mathrm{a}}$ & EMR $^{\mathrm{a}}$ \\
\hline $\begin{array}{l}\text { EST-SSR } \\
\text { (14 primer pairs) }\end{array}$ & 118 & 97.46 & 8.43 & 8.21 & 0.34 & 3.65 \\
$\begin{array}{l}\text { TRAP } \\
\text { (36 primer pairs) }\end{array}$ & 2184 & 94.87 & 60.67 & 57.56 & 0.33 & 24.85 \\
\hline
\end{tabular}

apowell et al. (1996b); DI = diversity index; EMR = effective multiplex ratio; MI = marker index.

revealed by TRAP markers (94.87\%) was lower as compared to EST-SSR (97.46\%), which clearly explained the role of EST-SSR as a better suited marker for the genotyping of the Diospyros genus. As well known, the utility of a given marker system is a balance between the level of polymorphism detected (DI) and the extent to which an assay can identify multiple polymorphisms. A convenient estimate of marker utility may therefore be devised from the product of information 


\section{Luo et al.}

content and effective multiplex ratio. MIs for the marker system studied are summarized in Table 4. TRAP showed high MI, as much as eight times higher than that of EST-SSR in Diospyros.

Similarity matrices were constructed based on shared allele analyses, and the average genetic similarity between genotypes was found to be lower in the case of SSRs markers $(0.626)$ compared to TRAP (0.662). The correspondence between the similarity matrices produced by the two different marker systems was analyzed using the Mantel test (Table 5). We observed a statistically high correlation $(\mathrm{P}<0.01)$, which showed that although both markers are effective in genotyping the species, a combined approach (EST-SSR+TRAP) would be significantly more effective in the genotyping and effective discrimination of the species. Dendrograms of 20 persimmon genotypes were constructed using the UPGMA clustering from the similarity coefficient data of EST-SSR and TRAP and the combined data of both markers. In TRAP, the 20 genotypes were generally divided into three clusters. The three related species formed an independent group that fell well outside of the clusters including all of the genotypes of $k a k i$ species. There were two groups in the kaki species cluster, Chinese native genotypes and Japanese native genotypes. Furthermore, the genotypes of known parental origins were clustered closely. 'Eshi 1' and 'Baogai-tianshi', which are both PCNA (pollination-constant nonastringent) originating from China, were clustered closely. However, 'Sifang-tianshi', another Chinese PCNA, fell out of the group of Chinese native genotypes, which was unexpected. 'Hiratane-nashi' is a rare nonaploid, and it was clustered with other normal Japanese hexaploid cultivars with a low similarity coefficient (Figure 3). However, there were some differences in the SSR tree. 'Hiratane-nashi' was clustered with the Chinese native genotypes, 'Fuyuu' was grouped with 'Sifang-tianshi,' and 'Eshi 1' did not cluster with 'Baogai-tianshi' (Figure 4). The tree constructed by combination data of both markers was very similar with the TRAP tree.

Table 5. Mantel test correlation coefficients among similarity matrices obtained using targeted region amplified polymorphism (TRAP) and expressed sequence tags-simple sequence repeat (EST-SSR) markers.

\begin{tabular}{lccc}
\hline & TRAP & EST-SSR & TRAP+EST-SSR \\
\hline TRAP & - & & - \\
EST-SSR & 0.902 & 0.915 & - \\
TRAP+EST-SSR & 0.999 & . & \\
\hline
\end{tabular}

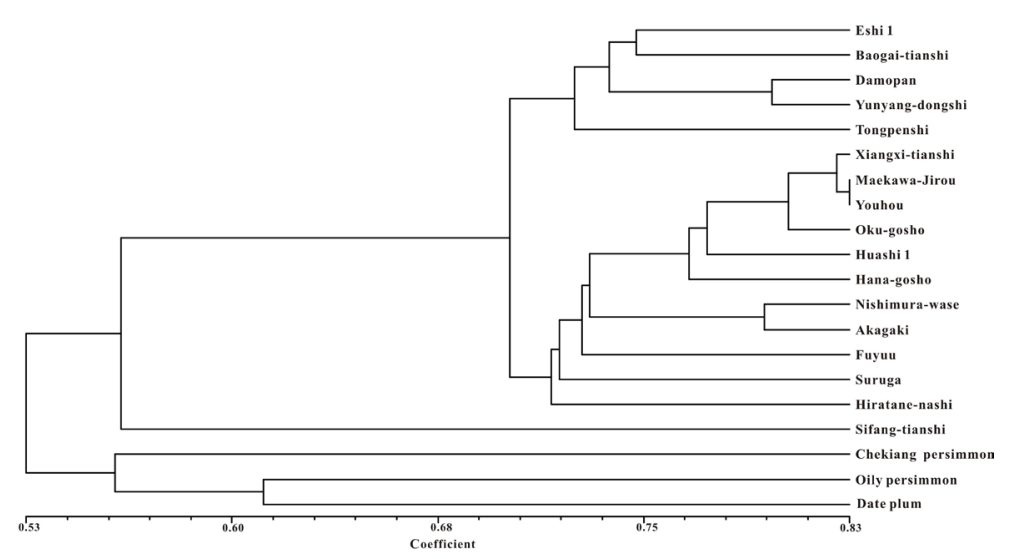

Figure 3. Dendrogram of 20 genotypes from the unweighted pair-group method with arithmetic averages cluster analysis based on targeted region amplified polymorphism analysis. 
EST-SSR and TRAP markers in persimmon

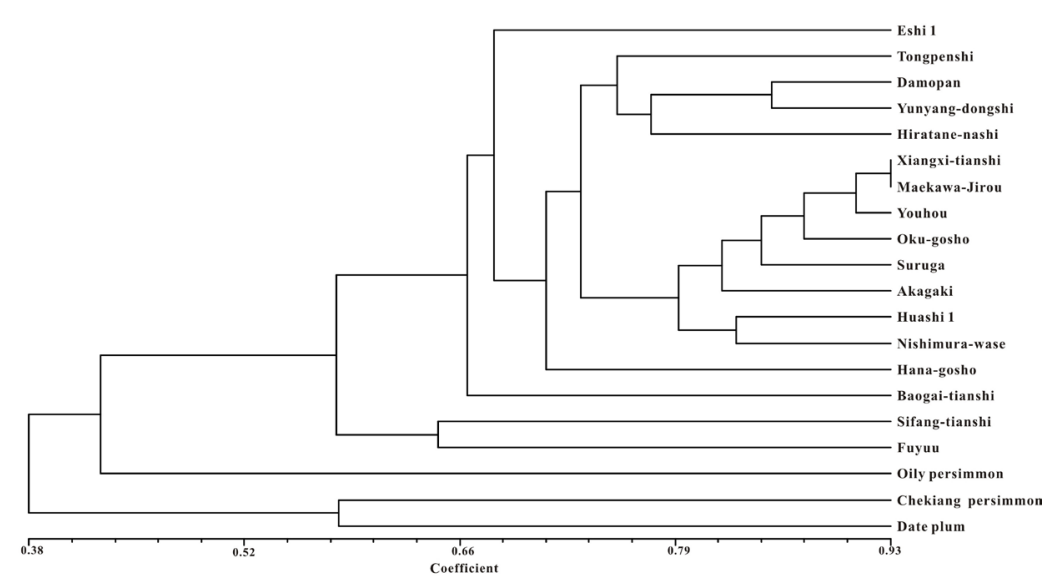

Figure 4. Dendrogram of 20 genotypes from the unweighted pair-group method with arithmetic averages cluster analysis based on expressed sequence tags-simple sequence repeats analysis.

The cophenetic correlation coefficients between the dendrogram and the original distance matrix for EST-SSR and TRAP were all significant. The values were $0.967(\mathrm{P}<0.01)$ for EST-SSR and $0.953(\mathrm{P}<0.01)$ for TRAP.

\section{DISCUSSION}

Of the 116 pairs of designed EST-SSR primers, 45 (38.79\%) did not show clear PCR amplifications in the 20 persimmon genotypes. The reasons for the absence may be due to the presence of a mismatch or the presence of large introns between two primers. Fourteen primer pairs effectively revealed polymorphisms, accounting for $19.72 \%$, higher than that in soybean $(12.8 \%)$ (Cardle et al., 2000) but lower than that in wheat (25\%) and barley (35\%) (Thiel et al., 2003). Differences in the polymorphism rates may be partly attributable to the relatedness or the number of genotypes tested. Generally, EST-SSRs show lower levels of polymorphism than genomic SSRs (Eujayl et al., 2002). An earlier report by Guo et al. (2006) revealed the development of 9 polymorphic (75\%) genomic SSR (gSSRs) and showed that the number of alleles ranged from 5 to 20 alleles per locus with an average of 13.8. It should be mentioned here that they studied 30 persimmon cultivars. Also, Soriano et al. (2006) reported that 22 polymorphic (59.46\%) gSSR markers represented from 2 to 8 alleles per locus with an average of 5.14 when estimated in 12 persimmon cultivars. In comparison to the above reports based on analysis of the 20 persimmon genotypes by the 14 polymorphic EST-SSRs (19.72\%), the number of alleles detected ranged from 4 to 14 (with an average of 7.86). The difference in the polymorphic level among these studies may result from the nature of the SSRs (genomic versus EST-derived), the relatedness of the genotypes or simply the number of genotypes tested.

In comparison to the EST-SSR markers, the TRAP technique is a relatively highthroughput PCR-based marker system and very efficient compared to other marker systems which use arbitrary primers for amplification of the non-coding region of the genome. This marker has been extensively used in spinach to assess the genetic diversity and has shown a significant amount of polymorphism (19.5\%) across 38 germplasms and 10 commercial hy- 
C. Luo et al.

brids (Hu et al., 2007). Furthermore, the TRAP technique generates a greater number of amplicons, comparable to the AFLP technique. Using 142 Buxus genotypes, Van Laere et al. (2011) generated 750 polymorphic AFLP fragments from 3 primer combinations. In comparison, we used varietal and wild type persimmon to reveal a total of 2072 polymorphic bands from 36 primer pairs with an average of 57.56 polymorphic markers per reaction.

In our study, we effectively demonstrated the development and characterization of ESTSSR primer pairs and TRAP primer combinations for the genus Diospyros. We obtained more amplicons in the case of TRAP compared to EST-SSR. Since both markers represent the functional coding region of the genome, this report presents the development of functional candidate markers in genus Diospyros. We used MI and its components-DI and EMR to examine the overall efficiency of the two marker systems as applied to persimmon (Du et al., 2009b). It was useful to analyze each of these components and their ramifications individually. Comparison of the diversity index calculated from the experimental data exhibited that EST-SSR was more polymorphic, which was in agreement with previous research in other plants (Milbourne et al., 1997; McGregor et al., 2000; Belaj et al., 2003; Panwar et al., 2010). However, TRAPs revealed high values of loci per assay unit, average number of polymorphic bands per assay unit, and high EMR, indicating that a large amount of genetic information could be detected using this marker, which was in keeping with the study by Alwala et al. (2006) and Hu et al. (2007). In TRAP the value of MI produced by DI and EMR was about seven times higher than that in EST-SSR, indicating that TRAP is a marker system with a good comprehensive performance.

\section{ACKNOWLEDGMENTS}

Research supported by the Natural Science Foundation of China (\#30871686, \#30921002) and the Special Scientific Research Fund of Agricultural Public Welfare Profession of China (\#200903044). The authors are grateful to Professor Jihong Liu for manuscript review.

\section{REFERENCES}

Alwala S, Suman A, Arro JA, Veremis JC, et al. (2006). Target region amplification polymorphism (TRAP) for assessing genetic diversity in sugarcane germplasm collections. Crop Sci. 46: 448-455.

Bassam BJ, Caetano-Anolles G and Gresshoff PM (1991). Fast and sensitive silver staining of DNA in polyacrylamide gels. Anal. Biochem. 196: 80-83.

Belaj A, Satovic Z, Cipriani G, Baldoni L, et al. (2003). Comparative study of the discriminating capacity of RAPD, AFLP and SSR markers and of their effectiveness in establishing genetic relationships in olive. Theor. Appl. Genet. 107: 736-744.

Cardle L, Ramsay L, Milbourne D, Macaulay M, et al. (2000). Computational and experimental characterization of physically clustered simple sequence repeats in plants. Genetics 156: 847-854.

Charters YM, Robertson A, Wilkinson MJ and Ramsay G (1996). PCR analysis of oilseed rape cultivars (Brassica napus L. ssp. oleifera) using 5'-anchored simple sequence repeat (SSR) primers. Theor. Appl. Genet. 92: 442-447.

Chen CX, Grosser JW, Ćalović M, Serrano P, et al. (2008). Verification of mandarin and pummelo somatic hybrids by expressed sequence tag-simple sequence repeat marker analysis. J. Am. Soc. Hortic. Sci. 133: 794-800.

Cloutier S, Niu ZX, Datla R and Duguid S (2009). Development and analysis of EST-SSRs for flax (Linum usitatissimum L.). Theor. Appl. Genet. 119: 53-63.

Doyle JJ and Doyle JL (1990). Isolation of plant DNA from fresh tissue. Focus 12: 13-15.

Du XY, Zhang QL and Luo ZR (2009a). Comparison of four molecular markers for genetic analysis in Diospyros L. (Ebenaceae). Plant Syst. Evol. 281: 171-181.

Du XY, Zhang QL and Luo ZR (2009b). Development of retrotransposon primers and their utilization for germplasm identification in Diospyros spp. (Ebenaceae). Tree Genet. Genomes 5: 235-245.

Durand J, Bodenes C, Chancerel E, Frigerio JM, et al. (2010). A fast and cost-effective approach to develop and map EST- 


\section{EST-SSR and TRAP markers in persimmon}

SSR markers: oak as a case study. BMC Genomics 11: 570 .

Eujayl I, Sorrells ME, Baum M and Wolters P (2002). Solation of EST-derived microsatellite markers for genotyping the A and B genomes of wheat. Theor. Appl. Genet. 104: 399-407.

Gasic K, Han YP, Kertbundit S, Shulaev V, et al. (2009). Characteristics and transferability of new apple EST-derived SSRs to other Rosaceae species. Mol. Breed. 23: 397-411.

Geuna F, Toschi M and Bassi D (2003). The use of AFLP markers for cultivar identification in apricot. Plant Breed. 122: 526-531.

Guo DL and Luo ZR (2006). Development of SSR primers using ISSR-PCR in Diospyros kaki Thunb. Mol. Ecol. Notes 6: 886-887.

Guo DL and Luo ZR (2008). Microsatellite isolation and characterization in Japanese persimmon (Diospyros kaki). Biochem. Genet. 46: 323-328.

Guo DL and Luo ZR (2011). Genetic relationships of the Japanese persimmon Diospyros kaki (Ebenaceae) and related species revealed by SSR analysis. Genet. Mol. Res. 10: 1060-1068.

Hu JG and Vick BA (2003). Target region amplification polymorphism: a novel marker technique for plant genotyping. Plant Mol. Biol. Rep. 21: 289-294.

Hu JG, Mou B and Vick BA (2007). Genetic diversity of 38 spinach (Spinacia oleracea L.) germplasm accessions and 10 commercial hybrids assessed by TRAP markers. Genet. Resour. Crop Evol. 54: 1667-1674.

Hu J, Li J, Liang F, Liu L, et al. (2010). Genetic relationship of a cucumber germplasm collection revealed by newly developed EST-SSR markers. J. Genet. 89: e28-e32.

Kumar Yadav H, Ranjan A, Asif MH and Mantri S (2011). EST-derived SSR markers in Jatropha curcas L. development, characterization, polymorphism, and transferability across the species/genera. Tree Genet. Genomes 7: 207-219.

Lalitha S (2000). Primer Premier 5. Biotechnol. Softw. Internet Rep. 1: 270-272.

Li G and Quiros CF (2001). Sequence related amplified polymorphism (SRAP), a new marker system based on a simple PCR reaction: Its application to mapping and gene tagging in Brassica. Theor. Appl. Genet. 103: 455-461.

Lima LS, Gramacho KP, Pires JL, Clement D, et al. (2010). Development, characterization, validation, and mapping of SSRs derived from Theobroma cacao L.- Moniliophthora perniciosa interaction ESTs. Tree Genet. Genomes 6: 663-676.

Liu ZH, Anderson JA, Hu J and Friesen TL (2005). A wheat intervarietal linkage map based on microsatellite and target region amplified polymorphism markers and its utility for detecting quantitative trait loci. Theor. Appl. Genet. 111: 782-794.

McGregor CE, Lambert CA, Greyling MM, Louw JH, et al. (2000). A comparative assessment of DNA fingerprinting techniques (RAPD, ISSR, AFLP and SSR) in tetraploid potato (Solanum tuberosum L.) germplasm. Euphytica 113: 135-144.

Miklas PN, Hu J, Grunwald NJ and Larsen KM (2006). Potential Application of TRAP (targeted region amplified polymorphism) Markers for Mapping and Tagging Disease Resistance Traits in Common Bean. Crop Sci. 46: 910-916.

Milbourne D, Meyer R, Bradshaw JE, Baird E, et al. (1997). Comparison of PCR-based marker systems for the analysis of genetic relationships in cultivated potato. Mol. Breed. 3: 127-136.

Panwar P, Nath M, Yadav VK and Kumar A (2010). Comparative evaluation of genetic diversity using RAPD, SSR and cytochrome P450 gene based markers with respect to calcium content in finger millet (Eleusine coracana L. Gaertn.). J. Genet. 89: 121-133.

Powell W, Machray GC and Provan J (1996a). Polymorphism revealed by simple sequence repeat. Trends Plant Sci. 1: 215-222.

Powell W, Morgante M, Andre C, Hanafey M, et al. (1996b). The comparison of RFLP, RAPD, AFLP and SSR (microsatellite) markers for germplasm analysis. Mol. Breed. 2: 225-238.

Rohlf FJ (2000). NTSYSpc, Numerical Taxonomy and Multivariate Analysis System, Version 2.10e. Exeter Publications, New York.

Sablok G, Luo C, Lee WS, Rahman F, et al. (2011). Bioinformatic analysis of fruit-specific expressed sequence tag libraries of Diospyros kaki Thunb.: view at the transcriptome at different developmental stages. 3 Biotech. 1: 35-45.

Soriano JM, Pecchioli S, Romero C, Vilanova S, et al. (2006). Development of microsatellite markers in polyploid persimmon Diospyros kaki L. from an enriched genomic library. Mol. Ecol. Notes 6: 368-370.

Thiel T, Michalek W, Varshney RK and Graner A (2003). Exploiting EST databases for the development and characterization of gene-derived SSR-markers in barley (Hordeum vulgare L.). Theor. Appl. Genet. 106: 411-422.

Van Laere K, Hermans D, Leus L and Van Huylenbroeck J (2011). Genetic relationships in European and Asiatic Buxus species based on AFLP markers, genome sizes and chromosome numbers. Plant Syst. Evol. 293: 1-11.

Yakushiji H and Nakatsuka A (2007). Recent persimmon research in Japan. Jpn. J. Plant Sci. 1: 42-62. 